\title{
Impacts as Triggers for Weather-Related Decision Making: Observations at the Berlin Fire Brigade Control and Dispatch Center
}

\author{
Thomas Kox ${ }^{1,2,3} \cdot$ Catharina Lüder $^{1}$
}

Accepted: 11 May 2021 / Published online: 26 May 2021

(C) The Author(s) 2021

\begin{abstract}
This article presents the results of a series of ethnographic observations at the Berlin fire brigade control and dispatch center during routine and severe weather situations. The weather-related challenges of a fire brigade lie between the anticipation of events and their potential consequences, and the ad hoc reactions to actual impacts of weather. The results show that decisions and actions related to high impact weather are not necessarily motivated by weather warnings alone. Instead, they are reactions to the experience of impacts, for example, an increased number of missions or emergency calls. Impacts are the main trigger for the decision making. Weather is one additional external factor that influences the operational capability of a fire brigade. While commanding officers in a fire brigade control and dispatch center experience weather primarily through technical equipment, verified by ground truth, observations showed that direct personal contact with the regional weather service and colleagues on the ground takes on a greater role in actual severe weather situations. The observations point to the need for increased interagency communication between the emergency services, the weather service, and other organizations to integrate weather information, impacts, and non-weather-related tasks into coherent weather-related decision making.
\end{abstract}

Thomas Kox

t.kox@1mu.de

1 Institute of Computer Science, Freie Universität Berlin, 12165 Berlin, Germany

2 Hans-Ertel-Center for Weather Research Berlin, 12165 Berlin, Germany

3 Department of Geography, Ludwig-Maximilians-Universität München, 80333 Munich, Germany
Keywords Berlin · Emergency services · Fire brigades - Impact-based emergency response $\cdot$ Interagency communication $\cdot$ Weather-related decision making

\section{Introduction}

Fire brigades are the main operational forces in emergency management at the community or county level in Germany. Their common task is to protect lives and livelihoods against serious threats and potentially disastrous events, as well as to prevent, limit, or manage the ultimate impacts of these events. Fire brigades are sometimes referred to as "hybrid organizations," as they are characterized by a tension between the bureaucratic provision and ensuring of safety and security - shaped by hierarchies, divisions of labor, and specializations - and the handling of turbulence and the unexpected, shaped by flexibility and openness (Apelt and Tacke 2012; Apelt 2014). Thus, there is a dissonance between advance strategic planning to use resources purposefully, and the flexibility to respond tactically to fluctuations in demand for resources during disastrous events.

Information on potentially disastrous events is critical for the allocation of human and material resources to ensure preparedness. The aim is to avoid delays in response to emergency calls and disruptions to organizational routines and "to ensure the preparedness to respond and the organization's ability to act" (Kox et al. 2018, p. 125). For fire brigades, this means that they need to develop adaptive routines to be prepared for rare events and to remain open to new developments and real surprises (Apelt 2014).

Disaster risk reduction measures always have anticipatory elements that may prompt action. For severe weather 
situations, weather warnings may become the primary source to prepare for action. Official weather warnings of the German Weather Service (Deutscher Wetterdienst, DWD) usually reach the fire brigade at their respective regional fire brigade control and dispatch center (hereafter referred to as dispatch center). In the dispatch center incoming calls to the emergency telephone number for firefighting and ambulance services (112) are answered and the resulting missions are dispatched and coordinated. Weather-related missions are typically marked with alerting terms such as "tree," "traffic obstruction," or "water damage" (Pardowitz 2018), indicating the significance of the consequences of severe weather for weather-related decision making.

The consequences of severe weather are taken into account by the current development of impact-based forecasting systems, which constitute a shift from weather forecast provision, with a focus on meteorological conditions alone, to weather forecasts that incorporate information about the consequences or impacts associated with the meteorological conditions (WMO 2015; Potter et al. 2018). Ground truth information, for example, about traffic obstructions due to the flooding of roads, as a result of sudden heavy rainfall, or due to a tree that has fallen on a road, can be helpful support for action due to its practical relevance (Kox et al. 2018).

While the importance of time is already being discussed for anticipatory actions in disaster risk reduction and related activities-such as providing probabilistic weather information to gain additional lead time (Fundel et al. 2019) — providing impact information for taking adequate action poses new challenges for the modeling and communication of warnings and requires new perspectives on what the word "impacts" actually means to users, and how these impacts can be used in decision making. Yet little is known from the perspectives of those in relevant agencies who would be involved in the implementation of impactbased forecasts, such as forecasters and emergency managers (Potter et al. 2021). Knowledge within the weather community (atmospheric scientists, meteorological forecasters) about the practical relevance of weather and impact information for emergency services, and the potential implementation and use of such information, is limited due to the highly specialized working environment of emergency services and affiliated fields, and the difficulty of accessing information about how these services actually deal with weather forecasts in their day-to-day work. It is precisely these impacts and challenges that the emergency services and other agencies face in severe weather situations that are not comprehensively known to the weather community. Yet for the development of impact-based forecasts, it is indispensable to know what "impact" actually means to the recipient of the information and how communication procedures work within different target groups. Therefore, the World Meteorological Organization (WMO) has made communication a core theme of its High Impact Weather initiative that aims at the understanding of the user needs that is required for improved weather warnings (Taylor et al. 2018; Zhang et al. 2019).

Following Créton-Cazanave and Lutoff (2013, p. 1470) weather warnings are not merely understood as a one-way communication event but rather as a "socio-technical process by which the reality of a given situation is taken into consideration in order to establish its meaning, so as to constitute and coordinate action in a context of assumed danger." Therefore, it is important to look at the actual practices of users of weather warnings, to observe and describe them (Créton-Cazanave and Lutoff 2013). It also raises the question of which technical communication equipment is available to the dispatch center's commanding officers and how they use it to deal with threats. To address these issues, we posed the following two questions:

- What are the practices related to weather information in dispatch centers?

- What challenges do firefighters face in high impact weather situations?

In Sect. 2, we introduce the research design and method used for this study. In Sect. 3, we discuss the practices in the dispatch center related to weather information, with a focus on routine weather situations and the meaning of weather impacts and the technical means of communication. We then discuss the weather-related challenges with a focus on severe weather situations (Sect. 4), and draw conclusions (Sect. 5).

\section{Method}

Most studies concerned with decision making in severe weather situations by the public or more sophisticated user groups such as emergency services have an experimental character and do not include real-world settings (Morss et al. 2008). They often use hypothetical scenario questionnaires, interviews, or laboratory designs, and are limited by a lack of real consequences for the decision makers. In contrast, ethnographic approaches allow the observation of practices in real-life environments and help in the study of real-life decision making (Créton-Cazanave 2009).

A mix of semistructured direct observations and ethnographic interviews was chosen for this study. The observations were limited to the commanding on-duty officer in the dispatch center's control room as the commanding officer functions as the dispatch center's information hub and receives all official weather warnings through a diverse communication infrastructure. The observation period 
spanned five weeks, from 20 June to 24 July 2017, and was carried out by the two authors and a third observer on nine observation days. Each visit lasting between 2 and $5 \mathrm{~h}$ (total observation time of $35 \mathrm{~h}$ ). June and July were chosen because of the probability of thunderstorms and heavy rain. During the study period, the fire brigade declared an "exceptional weather situation status" (not to be confused with a state of emergency) on two days (22 and 29 June) due to thunderstorms and extreme continuous rainfall for almost $23 \mathrm{~h}$ on 29 June. Organizational actions (for example, coping with the disruptions caused by the weather events) and position-specific actions (for example, receiving and transmitting weather information) were the focus of the investigation.

\section{How Weather and Weather-Impact Information is Processed in the Berlin Fire Brigade's Dispatch Center}

The commanding officer's room is on the first floor of the dispatch center building. A wide window front opposite provides a view of the heart of the control center-the large room where emergency calls are answered and the coordination and dispatching of missions takes place. On average, there are about 2,600 emergency calls a day in Berlin, from which about 1,250 missions follow. About $80 \%$ of all missions refer to ambulance services, while operations without the direct involvement of an ambulance service make up a significantly smaller proportion. Around 10,000 missions per year can be classified as weather-related missions.

The middle of the control center is dominated by a wide desk, which holds several monitors, keyboards, telephones, and all sorts of documents. The left wall is covered with a map of the Berlin city area, with an overview of the different fire brigade directorates, and a large pin board with different notifications, including the latest DWD weather warning faxes that arrive here. The room is conceptualized as a single workstation around which diverse information infrastructures are arranged. The commanding officer is the only person on duty in this room and is thus the only one with access to certain information systems, such as the DWD's online portal FeWIS (FeuerwehrWetterinformationssystem, the fire brigade weather information system, see Fundel et al. 2019) that provides information tailored to the fire brigade's specific region, including up-to-date observational data, satellite and radar imageries, and tools to track thunderstorm cells and their movement. Communication from the room takes place predominantly by telephones and e-mails.

The workstation is shared in 12-h shifts. During the handover a situation picture includes reports on the development of emergency calls and missions, as well as an explanation of special missions (for example, major fires or accidents), and the current and expected weather conditions. At the beginning of the shift, the commanding officer obtains detailed information about the weather forecast for the next few hours using the FeWIS and the faxes of the DWD. For inconspicuous weather conditions that do not directly affect the work of the fire brigade, the officer just briefly takes note of the information. It is central to the commanding officers' work to keep track of all issues that could have an impact on the operational capability, the ability to respond, and the processing of missions. Through purposeful and efficient coordination and disposition of resources, the organization can promptly and appropriately react to disruptive events and emergencies. The commanding officers have developed routines of "collecting, comparing, and blending different information about the uncertain event and its uncertain outcomes within the situation assessment to validate the information" (Kox et al. 2018, p. 126). Checking weather information is thus incorporated into everyday routines. On a calm day without severe weather, major fires, or accidents, the commanding officer obtains information (actively) and gets informed (passively) about the weather by reading the warnings and reports that come by fax or from the FeWIS.

In severe weather situations information on the impacts of the weather, such as flooded streets, fallen trees, or damaged infrastructure, becomes vital. The impact that the weather has on the fire brigade's ability to respond and the processing of missions depends on external factors such as the time of day and the day of the week (for example, brightness, daytime and nighttime population, commuter movements), as well as the number of current missions or emergency calls, and on internal factors such as the working hours and workload of the firefighters, the accessibility of volunteer fire brigades, and the availability of resources such as cars and other technical equipment.

How does the commanding officer receive impact information? Always present on one of the central monitors is a list of all open missions and a list of all currently incoming emergency calls. Both lists fill and empty sometimes faster and sometimes slower, and sometimes (such as on 29 June 2017) their length increases dramatically, blinking red, due to the continuous rainfall that lasted for hours. Checking the lists is a regular task that is supported by the arrangement of the room's communication infrastructure. The monitor that permanently displays the FeWIS is located on the far right of the table. It is not the focus of attention of the commanding officer, but like all monitors it is visible at a glance. Without severe weather events, the weather does not play a prominent role in the day-to-day work of the fire brigade. It is part of complex and diverse information that is routinely handled. 
Besides the information that can be read on the monitors, the commanding officer is in liaison with units on the ground, senior staff, and colleagues within the dispatch center. Reports from the police, state, and district administrations, operators of transport infrastructures, or gas and electricity suppliers on the impact of the weather on their work complete the situation picture. In addition, the importance of handling press enquiries increases as severe weather situations, combined with an increase in emergency calls and missions, are followed by significant public interest.

Our observations revealed that practices of weather information are interwoven with many formal and informal routines, including monitoring and documentation of missions and emergency call lists, as well as occasional chats with colleagues. Dispatch centers are characterized by a culture that is saturated with technical instruments, rules, regulations, and documents that are used to validate initially incomplete or inaccurate information (Lauche 2012). In addition to technical means of communication, personal interactions like chats about weekend activities and leisure planning, or questions of whether to go home by bicycle or public transportation, become very important and combine work and non-work-related information gathering in order to obtain ground truth information about the impacts of the weather.

The observation results show the great importance of information technology, and the significance of the technical means is also symbolic of the remoteness of the control room and the solitude. There is little direct experience of what is happening outside and of what impact the weather has had or is having. The firefighters are no different from operational meteorologists and forecasters who also experience weather predominantly through technical and digital means and like to verify weather events by information from the ground (Fine 2007; Lüder 2019). Reports from dispatchers and scouts, by radio and mobile phone or personal phone conversations, provide ground truth information and break up this seclusion from time to time. A flashing of a specific mission in the mission list, a flashing light indicating an increase of queuing emergency calls, or the sound of the FeWIS jingle, show that audiovisual alerts often trigger actions. Sometimes live TV reports provide additional visual information of weather impacts in the city and the surrounding area. Paraphrasing the words of Ellebrecht and Jenki (2014), the present and immediate future become dominant temporal points of reference. Alerts divert the officers from their present activities and accelerate individual movements and organizational processes. The subsequent actions therefore appear as reactive to a weather warning or to reported impacts. Nowcasting data (up to $2 \mathrm{~h}$ before an event) seems to be the focal temporal domain for weather information. In this context, weather warnings seem to serve as justification for decisions and planning already made (Kox et al. 2018).

\section{Challenges of Weather Impacts}

Various challenges of weather impacts were repeatedly observed during the entire observation period, but mostly during the severe weather situation on 29 June 2017. Some of these challenges and the most prominent coping strategies are outlined below.

1. An increase of emergency call volume is one direct and important impact of severe weather on the organization. The increase can lead to waiting times for callers, especially with severe weather conditions that cover large areas where many are affected simultaneously (concentrated spatial affectedness). Furthermore, in terms of timing, the overlap of severe weather events with daily rush hours (that is, morning and evening commuting) also exacerbates the challenge. A prominent coping strategy is to appeal to the public by local TV, radio broadcasting, and web media to not dial the emergency number for minor damages. Nowcasting data (up to two hours before an event) and prewarning information (up to $48 \mathrm{~h}$ ) would be useful and most desirable to cope with this challenge.

2. An increase of deployment volume is not only related to the intensity but also the duration of a severe weather event. In the case of 29 June 2017, the rainfall continued for almost $23 \mathrm{~h}$. Several hours after the last raindrops the city's sewer system was still overloaded and roads were blocked (extended temporal affectedness). Consequently, emergency calls queued up in the list waiting to be addressed, and the number of open and unprocessed missions increased. Similar situations of extended temporal affectedness include major public events that are not necessarily associated with severe weather, for example, New Year's Eve. The list of open missions (and waiting times for emergency calls) is an indicator for the current workload of the dispatch center and need for action. A fire brigade is set to a certain capacity (for example, number of staff on duty), and precautionary adjustments (for example, rescheduling staff) have to be made sometimes days before an event might happen to ensure the preparedness to respond. Early warning information (up to several days) can be of value as it allows for planning in advance. While nowcasting data remain the focal temporal domain for decision making during a weather event, early warning information is used to schedule 
weather-critical processes and heighten internal awareness.

3. Bottlenecks in the availability and operational readiness of material, vehicles, and personnel can occur, for example, as a result of a local increase in mission volumes, or when units are tied to a specific location. Scouts can set priorities for mission management and, by declaring an "exceptional weather situation status," vehicles can be manned differently, and personnel and material can be distributed more flexibly between missions. In a large city such as Berlin alerting volunteer fire brigades increases the availability of additional resources. In the dualism of professional and volunteer firefighters, the hybridity of the fire brigade becomes particularly clear. It does not seem very effective to provide professional fire brigades for the entire fire and disaster protection at all times. Instead, volunteers are called in for emergencies and extreme situations (see Apelt 2014). This gives the organization a degree of both stability and flexibility.

4. Severe weather events with special public interest can lead to increased press enquiries and interagency communication, especially telephone calls from different administrations, the police, or infrastructure operators. The commanding officer collects and bundles the information in order to support coordination. This can be referred to as what Ellebrecht and Jenki (2014) called the centralized steering structure of a dispatch center. Cooperation with other authorities is particularly important in situations when technical experts or infrastructure managers are requested, when enquiries are forwarded to other specialist authorities, or when the DWD is contacted to clarify the weather forecast. While the commanding officer normally always works alone, on 29 June 2017 additional colleagues were called in, and some also volunteered to help during the event. This dualism of collegial and hierarchical structures is another sign of the hybridity of the fire brigade organization (Apelt 2014), and highlights the risk that could result from technical standardization attempts that might overlook the occasions that enable mutual support (Lauche 2012). Especially in non-routine situations where a lot is at stake, decision makers such as the commanding officer search for opportunities for discussion and joint decision making with colleagues (as well as with operational meteorologists) who can help to assess the situation. While in everyday situations decision making is a sole responsibility primarily based on technically delivered information, in exceptional situations decision making becomes a face-to-face process that is embedded in the complex hierarchical and personal systems of the organization.

\section{Conclusion}

The results of the observations give insight into the decision processes of the Berlin fire brigade dispatch center during everyday weather and severe weather situations with high impact on the local population or the organization itself. The study revealed that decisions and actions related to high impact weather are not necessarily triggered by the weather warnings prior to the event. Instead, they are a reaction to the impacts of the weather, that is, an increased number of missions or emergency calls. The weather-related challenges of a fire brigade lie in the expected, the expectable, and the unexpected; between the anticipation of events and their potential consequences, and the ad hoc reaction to the actual impacts of the weather. In order to better deal with these challenges, weather information needs to be put into the context of on-the-ground impacts. To achieve this, increased interagency communication between the emergency services and the regional weather service can help to understand forecast uncertainty, while communication with colleagues on the ground can help to verify impacts.

The series of observations identified the meaning of weather impacts and weather-related communication procedures of the Berlin fire brigade. For a more comprehensive picture of weather-related challenges, however, it would be beneficial to record longer periods of time in order to gain a more comprehensive understanding of routine and non-routine practices during severe and nonsevere weather situations. For the development of impactbased forecasts, it is recommended to aim for an international cross-country analysis of such challenges, communication procedures, and meanings of impact. With this knowledge, developers of impact-based forecasts will be able to make forecasts more user-oriented for decision making in disaster risk reduction. It is therefore appropriate that future work in this field should have a strong social science component dedicated to these questions.

Acknowledgements This research was carried out in the Hans-ErtelCentre for Weather Research at Freie Universität Berlin (Simmer et al. 2016). This research network of universities, research institutes, and the Deutscher Wetterdienst is funded by the BMVI (Federal Ministry of Transport and Digital Infrastructure). The authors would like to thank Clara Brune for her contributions during the fieldwork, and the Berlin fire brigade for allowing us to observe their day-to-day operations and for providing us with valuable insights into their tasks and duties. An earlier (German language) report of the preliminary analysis of our observations and the observational setting is available as Kox et al. (2019).

Open Access This article is licensed under a Creative Commons Attribution 4.0 International License, which permits use, sharing, adaptation, distribution and reproduction in any medium or format, as long as you give appropriate credit to the original author(s) and the source, provide a link to the Creative Commons licence, and indicate 
if changes were made. The images or other third party material in this article are included in the article's Creative Commons licence, unless indicated otherwise in a credit line to the material. If material is not included in the article's Creative Commons licence and your intended use is not permitted by statutory regulation or exceeds the permitted use, you will need to obtain permission directly from the copyright holder. To view a copy of this licence, visit http://creativecommons. org/licenses/by/4.0/.

\section{References}

Apelt, M. 2014. Organizations of emergency and rescue-An introduction from a socio-organizational perspective (Organisationen des Notfalls und der Rettung-Eine Einführung aus Organisationssoziologischer Perspektive). In Organizations and experts of emergency in the transformation of technology and culture of fire and rescue services (Organisationen und Experten des Notfalls. Zum Wandel von Technik und Kultur bei Feuerwehr und Rettungsdiensten). Zivile Sicherheit 7, ed. M. Jenki, N. Ellebrecht, and S. Kaufmann, 69-84. Berlin: LIT (in German).

Apelt, M., and V. Tacke. 2012. Introduction (Einleitung). In Handbook of organization types (Handbuch Organisationstypen), ed. M. Apelt, and V. Tacke, 7-20. Wiesbaden: Springer (in German).

Créton-Cazanave, L. 2009. Warning! The use of meteorological information during a flash-flood warning process. Advances in Science and Research 3(1): 99-103.

Créton-Cazanave, L., and C. Lutoff. 2013. Stakeholders' issues for action during the warning process and the interpretation of forecasts' uncertainties. Natural Hazards and Earth System Sciences 13(6): 1469-1479.

Ellebrecht, N., and M. Jenki. 2014. Organizations and experts of emergency: A research overview (Organisationen und Experten des Notfalls: Ein Forschungsüberblick). In Organizations and experts of emergency in the transformation of technology and culture of fire and rescue services (Organisationen und Experten des Notfalls. Zum Wandel von Technik und Kultur bei Feuerwehr und Rettungsdiensten). Zivile Sicherheit 7, ed. M. Jenki, N. Ellebrecht, and S. Kaufmann, 11-48. Berlin: LIT (in German).

Fine, G.A. 2007. Authors of the storm: Meteorologists and the culture of prediction. Chicago: University of Chicago Press.

Fundel, V.J., N. Fleischhut, S.M. Herzog, M. Göber, and R. Hagedorn. 2019. Promoting the use of probabilistic weather forecasts through a dialogue between scientists, developers and end-users. Quarterly Journal of the Royal Meteorological Society 57(7): 210-231.

Kox, T., C. Lüder, and C. Brune. 2019. Weather warnings in civil protection: Observations at a fire brigade control and dispatch center (Wetterwarnungen im Bevölkerungsschutz: Beobachtung einer Feuerwehrleitstelle). In Weather warnings: From extreme event information to communication and action: Contributions from the research project WEXICOM (Wetterwarnungen: Von der Extremereignisinformation zu Kommunikation und Handlung: Beiträge aus dem Forschungsprojekt WEXICOM). Schriftenreihe Sicherheit 25, ed. T. Kox, and L. Gerhold, 87-107. Berlin: Forschungsforum Öffentliche Sicherheit, Freie Universität Berlin (in German).

Kox, T., C. Lüder, and L. Gerhold. 2018. Anticipation and response: Emergency services in severe weather situations in Germany. Internation Journal of Disaster Risk Science 9(1): 116-128.

Lauche, K. 2012. New forms of cooperation (Neue Formen der Zusammenarbeit). In Human factors-The psychology of secure action in risk sectors (Human factors-Psychologie sicheren Handelns in Risikobranchen), 2nd edn, ed. P. Badke-Schaub, G. Hofinger, and K. Lauche, 205-218. Dordrecht: Springer (in German).

Lüder, C. 2019. Weather as a technology-supported process of knowing (Wetter als technisch vermittelter Wissensprozess). In Weather warnings: From extreme event information to communication and action: Contributions from the research project WEXICOM (Wetterwarnungen: Von der Extremereignisinformation zu Kommunikation und Handlung: Beiträge aus dem Forschungsprojekt WEXICOM). Schriftenreihe Sicherheit 25, ed. T. Kox, and L. Gerhold, 19-41. Berlin: Forschungsforum Öffentliche Sicherheit, Freie Universität Berlin (in German).

Morss, R.E., J.L. Demuth, and J.K. Lazo. 2008. Communicating uncertainty in weather forecasts: A survey of the U.S. public. Weather and Forecasting 23: 974-991.

Pardowitz, T. 2018. Modelling vulnerability to severe weather. Natural Hazards and Earth System Sciences 18(6): 1617-1631.

Potter, S., S. Harrison, and P. Kreft. 2021. The benefits and challenges of implementing impact-based severe weather warning systems: Perspectives of weather, flood, and emergency management personnel. Weather Climate, and Society 13(2): 303-314.

Potter, S., P. Kreft, P. Milojev, C. Noble, B. Montz, A. Dhellemmes, R.J. Woods, and S. Gauden-Ing. 2018. The influence of impactbased severe weather warnings on risk perceptions and intended protective actions. International Journal of Disaster Risk Reduction 30(Part A): 34-43.

Simmer, C., G. Adrian, S. Jones, V. Wirth, M. Göber, C. Hohenegger, T. Janjic, and J. Keller et al. 2016. HErZ: The German HansErtel Centre for weather research. Bulletin of the American Meteorological Society 97(6): 1057-1068.

Taylor, A.L., T. Kox, and D. Johnston. 2018. Communicating high impact weather: Improving warnings and decision making processes. International Journal of Disaster Risk Reduction 30(Part A): 1-4.

WMO (World Meteorological Organization). 2015. WMO guidelines on multi-hazard impact-based forecast and warning services. Geneva: WMO.

Zhang, Q., L. Li, B. Ebert, B. Golding, D. Johnston, B. Mills, S. Panchuk, and S. Potter et al. 2019. Increasing the value of weather-related warnings. Science Bulletin 64(10): 647-649. 